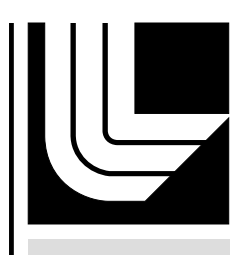

LAW RENCE LIVERM ORE N A T IO N A L LABORATORY

\title{
The National Ignition Facility: Enabling Fusion Ignition for the 21st Century
}

E. I. Moses, G. H. Miller, C. R. Wuest

September 21, 2004

Nuclear Fusion 
This document was prepared as an account of work sponsored by an agency of the United States Government. Neither the United States Government nor the University of California nor any of their employees, makes any warranty, express or implied, or assumes any legal liability or responsibility for the accuracy, completeness, or usefulness of any information, apparatus, product, or process disclosed, or represents that its use would not infringe privately owned rights. Reference herein to any specific commercial product, process, or service by trade name, trademark, manufacturer, or otherwise, does not necessarily constitute or imply its endorsement, recommendation, or favoring by the United States Government or the University of California. The views and opinions of authors expressed herein do not necessarily state or reflect those of the United States Government or the University of California, and shall not be used for advertising or product endorsement purposes. 


\title{
The National Ignition Facility: Enabling Fusion Ignition for the $21^{\text {st }}$ Century
}

\author{
George H. Miller, Edward I. Moses, Craig R. Wuest \\ Lawrence Livermore National Laboratory, P.O. Box 808 L-466, Livermore, CA 94551
}

\begin{abstract}
The National Ignition Facility (NIF) at Lawrence Livermore National Laboratory, when completed in 2008, will contain a 192-beam, 1.8-Megajoule, 500-Terawatt, ultraviolet laser system together with a 10 -meter-diameter target chamber and room for 100 diagnostics. NIF is housed in a 26,000 square meter environmentally controlled building and is the world's largest and most energetic laser experimental system. NIF provides a scientific center for the study of inertial confinement fusion and the physics of matter at extreme energy densities and pressures. NIF's energetic laser beams will compress fusion targets to conditions required for thermonuclear burn, liberating more energy than required to initiate the fusion reactions. Other NIF experiments will study physical processes at temperatures approaching $10^{8} \mathrm{~K}$ and $10^{11}$ bar; conditions that exist naturally only in the interior of stars and planets. NIF is currently configured with four laser beams activated in late 2002. These beams are being regularly used for laser performance and physics experiments and to date nearly 250 system shots have been conducted. NIF's laser beams have generated 106 kilojoules in 23-ns pulses of infrared light and over $16 \mathrm{~kJ}$ in 3.5 -ns pulses at the third harmonic $(351 \mathrm{~nm})$. A number of target experimental systems are being commissioned in support of experimental campaigns. This paper provides a detailed look the NIF laser systems, laser and optical performance, and results from laser commissioning shots. We also discuss NIF's high -energy density and inertial fusion experimental capabilities, the first experiments on NIF, and plans for future capabilities of this unique facility.
\end{abstract}

PACS numbers: 42.55.Rz, 42.60.By, 42.60.Jf, 42.60.Lh, 52.38.Dx, 52.57.-z, 52.72.+v, 62.50.+p

\section{INTRODUCTION}

The National Ignition Facility (NIF), under construction at the Lawrence Livermore National Laboratory (LLNL) for the U.S. Department of Energy and National Nuclear Security Administration (NNSA), provides a scientific center for the study of inertial confinement fusion and the physics of extreme energy densities and pressures. Construction of the building that houses the laser system was begun in May 1997 and completed in September 2001. The installation of all 192 ultra-clean and precision aligned beampath enclosures in NIF's two laser bays was completed in September 2003. In late 2002, NIF began activating its first four laser beamlines. By July 2003, NIF had delivered worldrecord single-laser energy performance at its primary wavelength of 1.06 micron, along with record energy levels at second and third harmonic wavelengths. When completed in 2008, NIF will provide 192 energetic laser beams to compress deuterium-tritium fusion targets to conditions in which they will ignite and burn, liberating more energy than is required from the laser to initiate the fusion reactions. NIF experiments will be conducted in a well-controlled laboratory setting to precisely study physical processes at a range of temperatures and pressures approaching up to 100 million $\mathrm{K}$ and 100 billion times atmospheric pressure. These conditions exist naturally only in the interior of stars and in nuclear weapons explosions. ${ }^{1-5}$ 


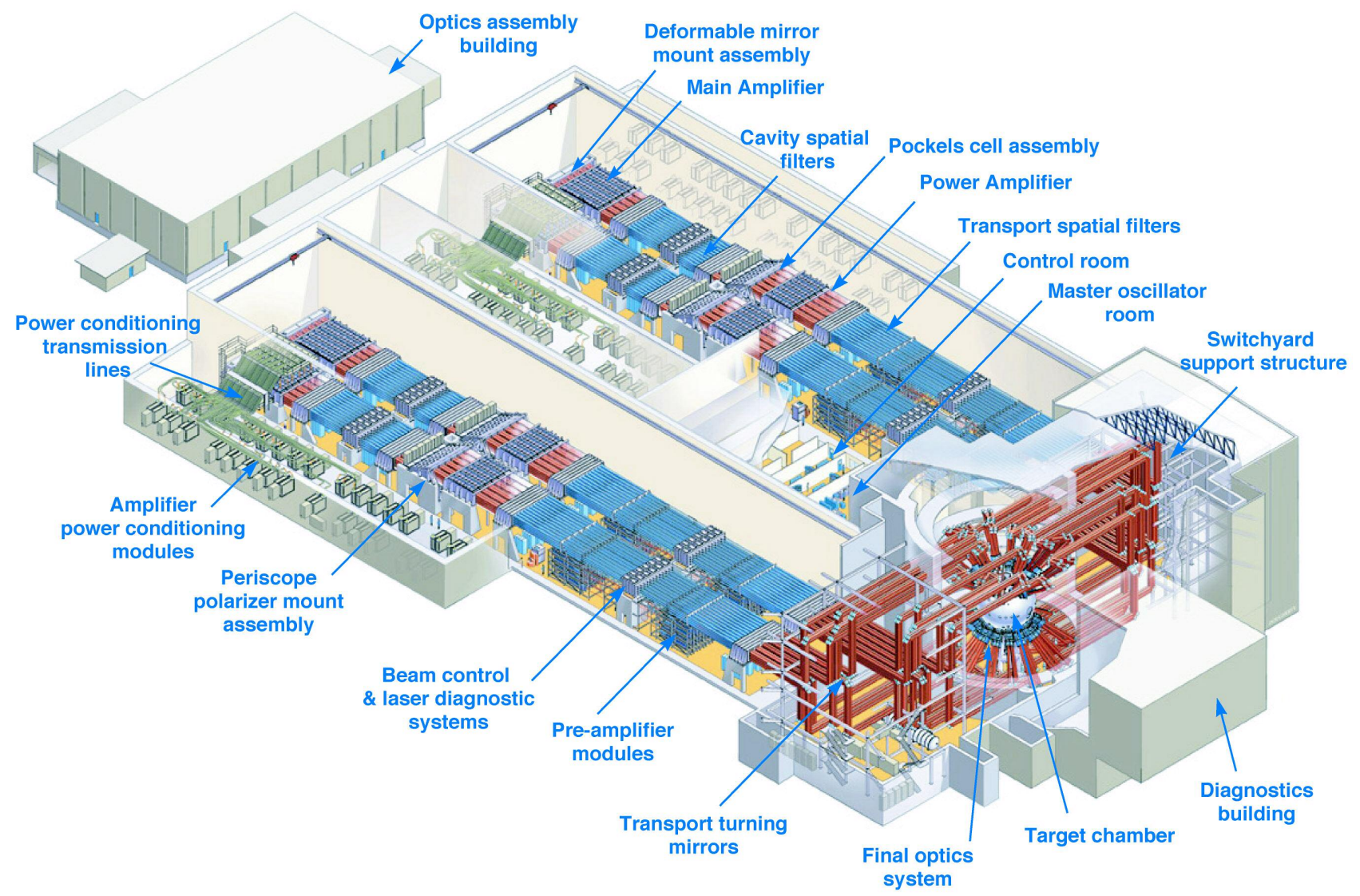

Figure 1. Schematic view of the National Ignition Facility showing the main elements of the laser system. The 10-meter diameter target chamber sets the scale for the facility.

\section{THE NIF LASER SYSTEM ARCHITECTURE}

Detailed descriptions of NIF's laser architecture and the performance of the laser system have been presented recently. ${ }^{6-21}$ The NIF laser system is shown in Figure 1. NIF is a highly parallel system of flashlamp-pumped neodymium-doped phosphate glass lasers. All NIF lasers are driven by the injection laser system, consisting of a single master oscillator, 48 pulse shaping systems that produce nanojoule level pulses with arbitrary waveform generation capability, and 48 preamplifier modules that condition and further amplify the pulses to the joule level prior to injection into the main laser system.

NIF's main laser system consists of two large amplifier units - the power amplifier, and the multi-pass or main amplifier. The amplifiers, with 16 glass slabs per beam, are arranged with 11 slabs in the main amplifier section and up to seven slabs per beam in the power amplifier section. Recent optimization studies indicate that three slabs per beam in the power amplifier are sufficient to meet NIF's power and energy requirements, while allowing for additional capability in the future. The amplifiers use 42 kilogram slabs, measuring $46 \mathrm{~cm} \times 81 \mathrm{~cm} \mathrm{x} 4.1 \mathrm{~cm}$, of neodymium-doped phosphate glass set vertically on edge at Brewster's angle to minimize reflective losses in the laser beam. ${ }^{22-23}$ 
A key component in each laser beamline is a plasma-electrode Pockels cell (PEPC), which acts as an optical switch. ${ }^{24}$ When combined with a polarizer, the PEPC allows light to pass through or reflect off the polarizer. The PEPC thus traps the laser light between two mirrors as it makes four one-way passes through the main amplifier system before being switched out to continue its way to the target chamber.

The Power Conditioning System located on either side of each laser bay stores up to 500 Megajoules of electrical energy for the 7,680 flashlamps used in NIF's large glass amplifier sections. ${ }^{25}$ The intense light from the flashlamps excites the neodymium in the laser slabs to provide optical gain at the primary 1.06 micron infrared wavelength of the laser.

After passing through the main laser system, each NIF laser beam contains up to approximately $20 \mathrm{~kJ}$ of infrared energy. Laser beams are transported in groups of 4 beams called quads through 10-story tall "switchyards" in argon-filled beam tubes and directed to the 10-meter target chamber. The NIF target chamber and final focusing system is designed with maximum flexibility for experimental users and includes over 100 diagnostic instrumentation and target insertion ports. The NIF Target Bay is adjacent to the Diagnostics Building that houses experimenters, experimenter data acquisition systems, and target preparation and storage areas. The entire laser system, switchyards, and target area is housed in an environmentally controlled building that maintains temperature and optical stability as well as cleanliness protocols external and internal to the laser beampath.

NIF's laser system architecture was developed following nearly three decades of experience building large lasers for the U.S. Inertial Confinement Fusion (ICF) Program. ${ }^{3}$ Experience gained with earlier laser systems at LLNL, e.g., the Shiva $10 \mathrm{~kJ}$ infrared laser $^{26}$, and the Nova $30 \mathrm{~kJ}$ ultraviolet laser ${ }^{27}$ allowed researchers to specify the requirements for the NIF laser architecture. These requirements were driven in part by studies carried out in the late 1980's and early 1990's indicating the geometric symmetry and amount of laser drive energy needed to uniformly compress, initiate and sustain fusion reactions in spherical deuterium-tritium filled targets using the indirect drive process, which is described below. ${ }^{1-2}$ These requirements taken together with advances in laser technology, including optics and electro-optical systems led to the NIF conceptual design in $1994 .{ }^{28}$ During initial operation, NIF is configured to operate in the "indirect drive" configuration, which directs the laser beams into cones in the upper and lower hemispheres of the target chamber. This configuration is optimized for illuminating the fusion capsule mounted inside cylindrical hohlraums using x-rays generated from the hot walls of the hohlraum to implode the capsule. ${ }^{29}$ In this design, NIF laser beams are directed in an 8 -fold symmetry around the azimuth of the target chamber and arranged in three cones of beams. For inertial fusion studies the beams will deliver 1.8 million joules (approximately 500 trillion watts of power) in a specially shaped pulse of laser energy in the near-ultraviolet (351 nanometer wavelength). The pattern of illumination in the hohlraum target and the sequence of ignition are shown in Figure 2. The energy available on NIF is approximately 60 times the energy of the Nova laser, which was operated at LLNL between 1983 and 1999 and currently operating 60-beam Omega Laser at the University of Rochester's Laboratory for Laser Energetics. ${ }^{30}$ 

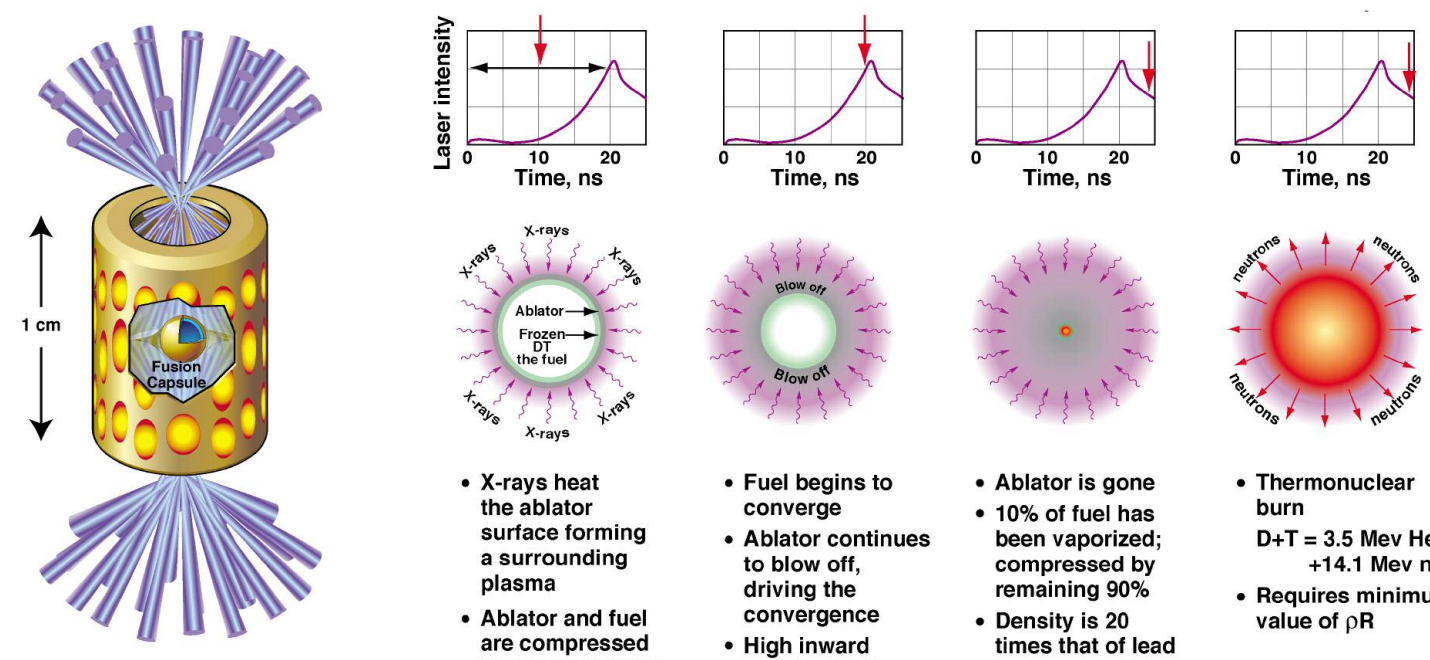
- X-rays heat the ablator surface forming a surrounding plasma
- Ablator and fuel are compressed by blow off of the hot surface material

- Thermonuclear burn $\mathrm{D}+\mathrm{T}=3.5 \mathrm{Mev} \mathrm{He}$ +14.1 Mev $n$ - Requires minimum value of $\rho \mathbf{R}$

Figure 2. A schematic representation of a NIF indirect-drive hohlraum target is shown on the left. NIF's 192 laser beams are grouped in 48 "quads" of four laser beams that are directed in opposite ends of the hohlraum to produce the X-ray drive. The time sequence on the right shows how the x-rays interact with the fusion capsule to create ignition and burn with energy gain.

\section{NIF OPTICS}

Among the many challenges in designing and building NIF has been the design, engineering, construction, and commissioning of what is arguably the largest precision optical instrument ever built. There are more than 7500 large optics of $40 \mathrm{~cm}$ or greater transverse size including laser amplifier glass slabs, lenses, mirrors, polarizers, and crystals. An additional 26,000 smaller optical components are used in NIF. The total area of precision optical surfaces in NIF is nearly 4,000 square meters. The optics and optical systems for NIF are the result of over thirty years of laser and optical materials research and development at national laboratories, universities, and in private industry throughout the world. ${ }^{31-38}$

Currently NIF's finishing vendors have finished approximately $30 \%$ of the optics required for NIF's 192 laser beams. NIF meter-scale optics suitable for high fluence operation with the required wavefront specification are being manufactured at a production rate of over 100 optics per month and we are following a schedule for completing production for all the necessary optics for 192 beam lines by 2007.

\section{ACTIVATION OF NIF'S FIRST LASER BEAMS}

In October 2001 the first laser light from NIF's master oscillator was generated in the master oscillator room. This master oscillator has demonstrated the required pulse shaping stability and accuracy for high contrast ignition pulses and other types of laser pulses that are of interest to NIF experimenters. In June 2002 the first preamplifier module was installed in the Laser Bay and routinely amplifies master 
oscillator pulses to the joule level. In April 2003 all 192 beampath enclosures were completed and ready for optics installation.

The first high energy third harmonic or $3 \omega$ laser light to the center of NIF's target chamber was achieved in January 2003 with approximately 1 kilojoule $(\mathrm{kJ})$ of laser energy focused onto a simple foil target. The energetic X-rays emitted from this target were measured with an X-ray pinhole imaging system called the Static X-ray Imager (SXI) ${ }^{39}$ mounted on the target chamber. In April $200310.6 \mathrm{~kJ}$ of $3 \omega$ light was produced in four beams and directed to a target in the target chamber. In late summer $200316 \mathrm{~kJ}$ of $3 \omega$ light in four beams was delivered to the target chamber for experiments. ${ }^{40} \mathrm{We}$ plan to complete a campaign of increasing energy $3 \omega$ shots through 2004 culminating in a full energy shot with $40 \mathrm{~kJ}$ of energy in four beams, thereby demonstrating NIF's maximum $3 \omega$ performance requirements.

A separate target chamber, known as the Precision Diagnostic System (PDS), which is located in one of NIF's switchyards, has also been used to fully characterize NIF's $1 \omega, 2 \omega$, and $3 \omega$ laser beam energy, power, and wavefront to validate and enhance computer models that predict laser performance. Any one of the four activated NIF beams can be directed into the PDS using a robotic mirror and transport system. Figure 3 shows examples of high-energy $2 \omega$ and $3 \omega$ beams imaged in the near field using the PDS.

NIF's highest $3 \omega$ single laser beam energy to date is $10.4 \mathrm{~kJ}$, equivalent to $2 \mathrm{MJ}$ for a fully activated NIF, exceeding the NIF energy point design of $1.8 \mathrm{MJ}$. This energy was achieved with $13.65 \mathrm{~kJ} 1 \omega$ drive in a $3.5 \mathrm{~ns}$ pulse. We have also conducted a series of shots generating green or $2 \omega$ laser light with single beam energy up to $11.4 \mathrm{~kJ}$ in a $5 \mathrm{~ns}$ square pulse. This is equivalent to nearly $2.2 \mathrm{MJ}$ on target for 192 beams. In July 2003, $26.5 \mathrm{~kJ}$ of $1 \omega$ light per beam was produced. This energy is $30 \%$ greater than the drive energy required for NIF. NIF has now demonstrated the highest energy $1 \omega, 2 \omega$, and $3 \omega$ beamlines in the world. High power campaigns have also been completed with drive power reaching 7 terawatts or about 5 gigawatts $/ \mathrm{cm}^{2}$. Figure 4 details energy and power achieved on a number of $1 \omega$ shots conducted over the past year.

Beam-to-beam synchronization has also been measured and adjusted to better than 6 picoseconds, which corresponds to approximately 1 part in 150,000 of the total beampath in NIF. Complex shaped ignition pulses as well as ramped and flat-in-time pulses with multi-kJ energies and pulse lengths up to $25 \mathrm{~ns}$ have also been demonstrated. 

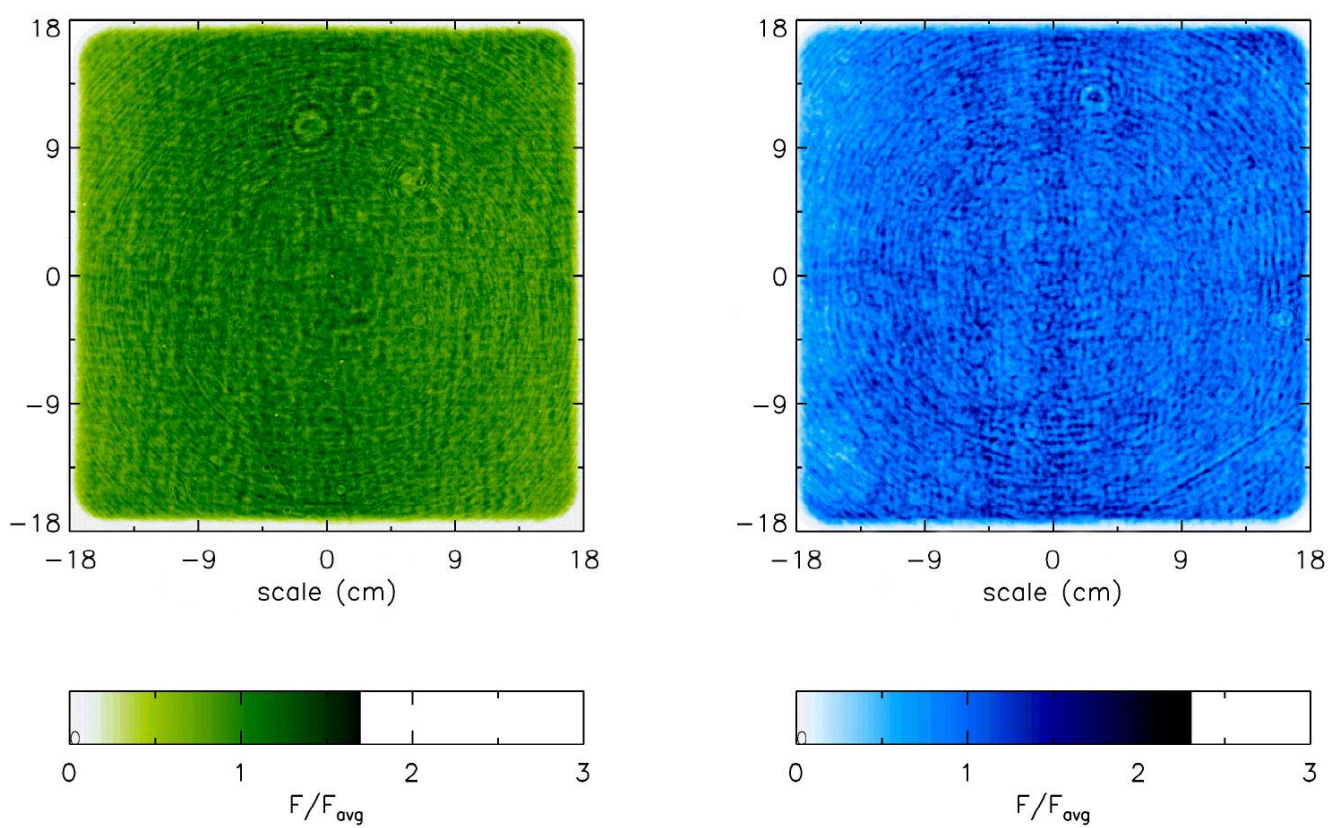

Figure 3. Near field image of an $11.4 \mathrm{~kJ} 2 \omega$ and $10.4 \mathrm{~kJ} 3 \omega$ NIF beams showing excellent contrast uniformity, exceeding NIF's requirements.

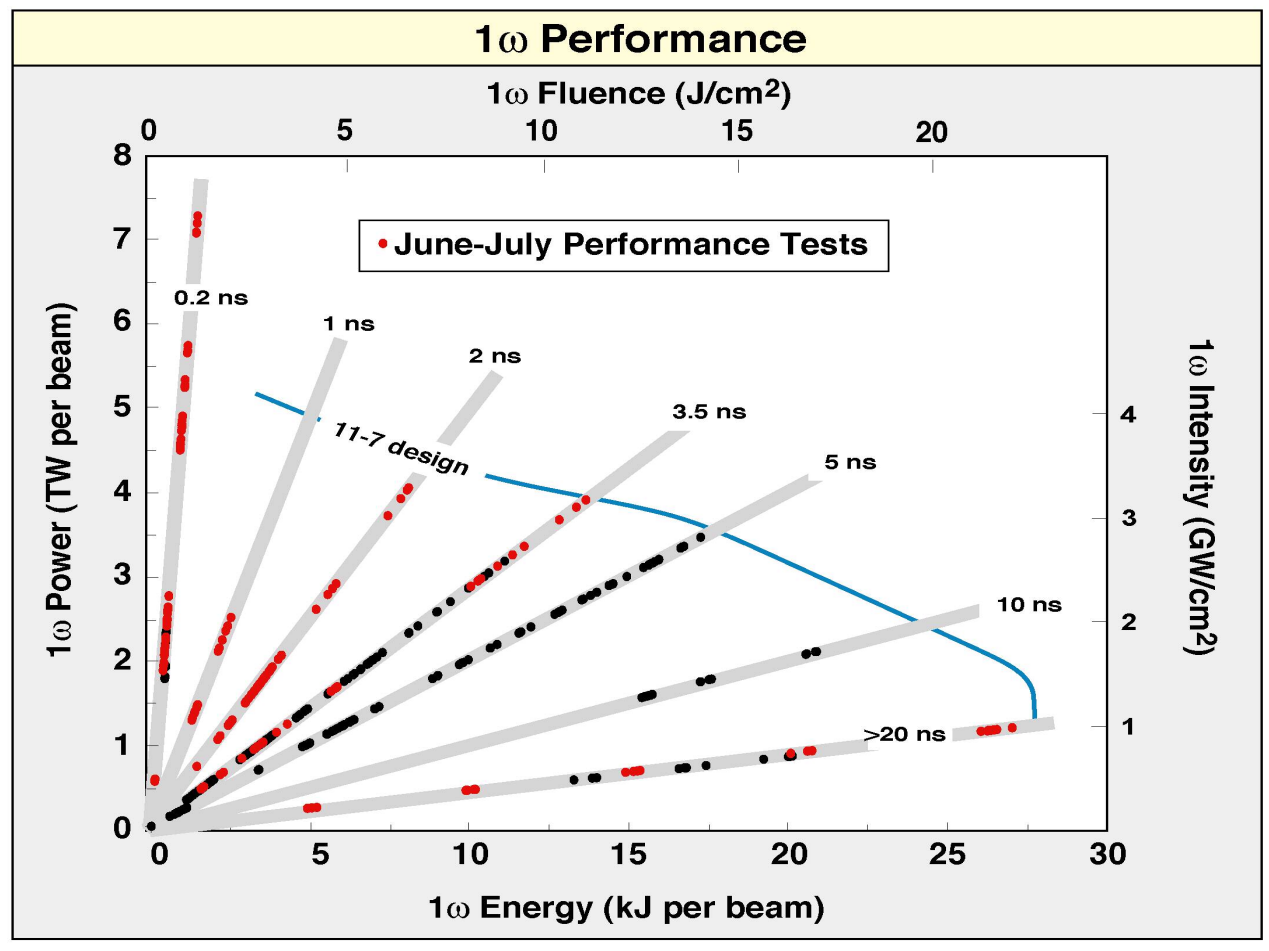

Figure 4. $1 \omega$ energy vs. power is plotted for a number of NIF performance shots. The plot also indicates the level where energy and power is limited by the available number of glass slabs in the main amplifier (11 slabs) and the power amplifier (7 slabs). 


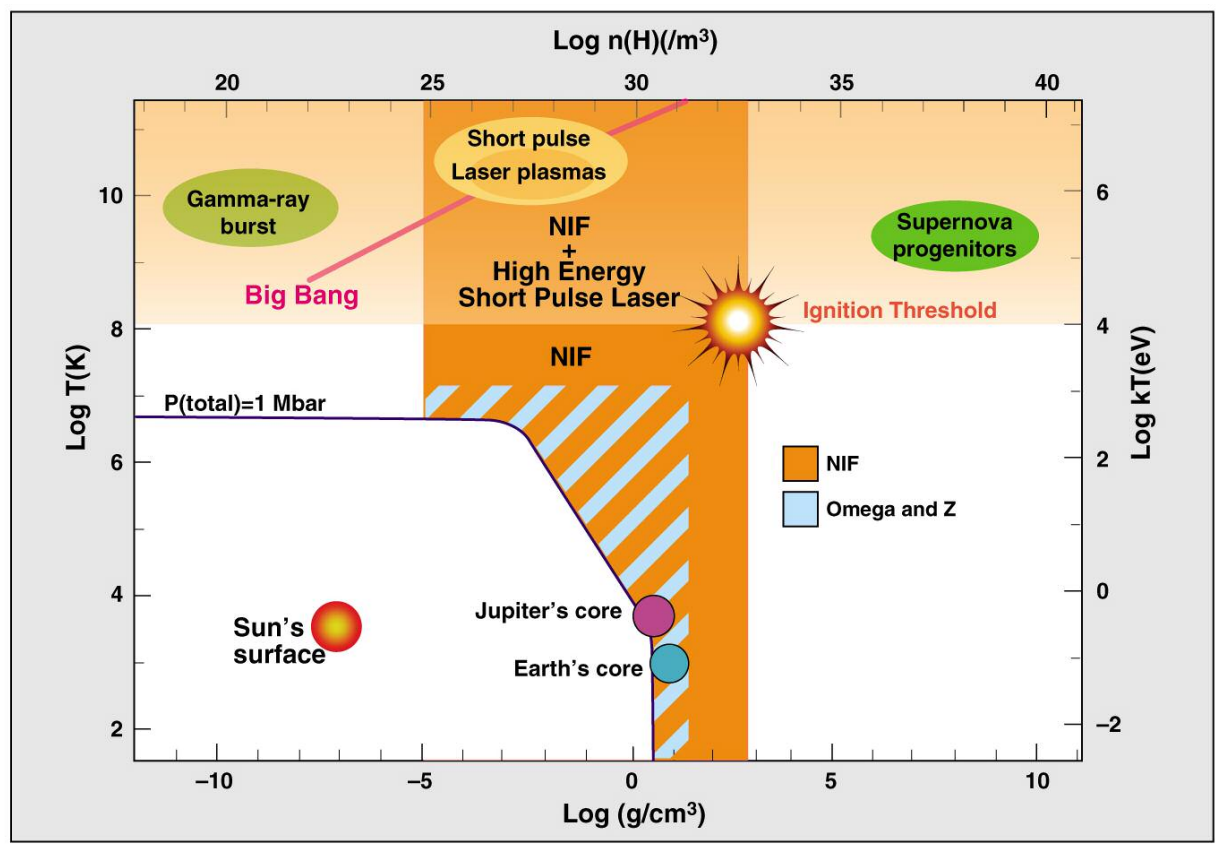

Figure 5. High-energy density is a prevailing condition in astrophysics. This figure shows how NIF can reach conditions of extreme temperature over a range of material densities that are relevant to a variety of astrophysical phenomena. NIF, with high-energy petawatt (HEPW) short-pulse laser capability, can reach conditions approaching those in existence near the time of the Big Bang. ${ }^{41}$

\section{EXPANDING SCIENTIFIC HORIZONS USING THE NATIONAL IGNITION FACILITY}

The National Academy of Sciences in the United States has recently recognized the exciting scientific frontiers becoming available at the next generation of high-energy-density experimental facilities. ${ }^{41}$ The National Ignition Facility will enable researchers to access unprecedented high-energy-density (HED) experimental regimes. Figure 5 displays one measure of NIF's physics reach as a function of temperature and density of materials. ${ }^{\dagger} \mathrm{NIF}$ will be able to reach conditions of matter that exist in the sun and larger stars, giant planets such as Jupiter, and brown dwarfs that are thought to make up a significant amount of the matter in our universe. With the planned addition of picosecond pulsed beams using modifications to NIF's current laser amplifier chain, NIF will be able to reach extreme states of matter more typically associated with nuclear and high-energy-physics accelerator experiments. In this way, NIF can explore the physics of matter at temperatures approaching those that existed in the very early universe. ${ }^{42}$

NIF's high-energy laser beams can be tailored for driving relatively large, uniform volumes. NIF can directly drive materials to tens of gigabars for pulse lengths of tens of nanoseconds. NIF is capable of providing a range of pulse lengths that under certain configurations can be as long as hundreds of nanoseconds. The ability to deliver extended high-energy drive allows new experimental measurements of equation of state (EOS), materials at high pressures, hydrodynamics, and radiation transport. For example, researchers can use NIF to study the properties of warm dense matter (WDM) - ap-

\footnotetext{
${ }^{\dagger}$ Figure adapted from Figure 1.1 in Reference 41.
} 
proximately solid density material at temperatures in the few $\mathrm{eV}$ to tens of $\mathrm{eV}$ range. Currently there is no theory that adequately describes WDM. ${ }^{43}$

NIF beams are also used to provide high x-ray fluences for high signal-to-noise radiography of dense matter. High-energy picosecond laser pulses can produce extremely high-brightness and high-energy $\mathrm{x}$-ray backlighter sources for radiographing WDM to fully resolve hydrodynamic features and material states. $^{44}$

Even with the first four beams of NIF, materials can be subjected to tens to one hundred megabars of pressure. Initial EOS experiments with the first four NIF beams are planned in the coming year that have a goal of exceeding $25 \mathrm{Mbar}$ in aluminum in a steady and uniform pressure wave. Isochoric heating with fusion ignition neutrons or high energy petawatt laser-generated ion beams when they become available in the coming decade provides an additional capability for shocking and heating materials to exotic physical states.

\section{LABORATORY ASTROPHYSICS}

Laboratory-based astrophysics experiments, simulating extreme physics phenomena heretofore inaccessible, are now becoming feasible for the first time on NIF. For example, supernovae explosion mechanisms can be simulated and studied using lasers to provide a better understanding of these highly dynamic and turbulent systems. ${ }^{45}$ Recent planar and spherical RT experiments on Nova and Omega showed that instabilities produced in these systems can be quantitatively studied. Figure 6 compares experiments conducted on Omega ${ }^{46}$ with simulations ${ }^{47}$ showing qualitative similarities in their behavior. Other scaled experiments using NIF are possible, for example, radiatively driven shocks that can lead to 2D jets and 3D spherical shocks observed in astrophysics.

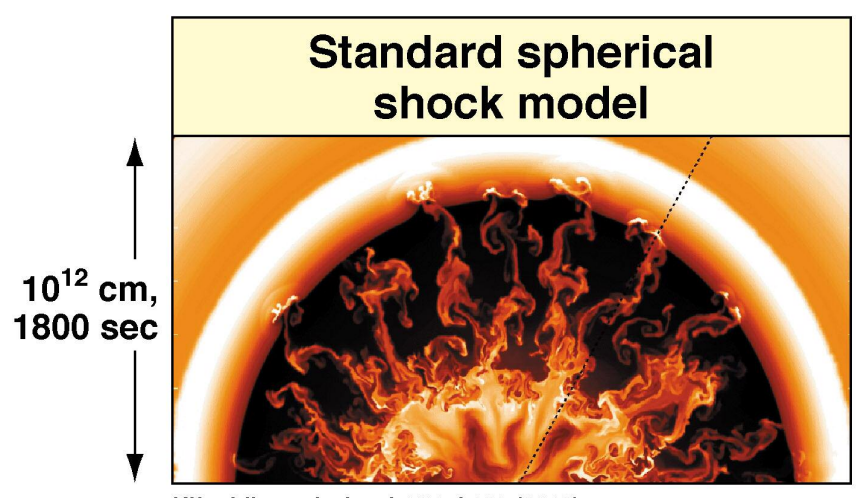

Kifonidis et al., Ap. J. 531, L123 (2000)

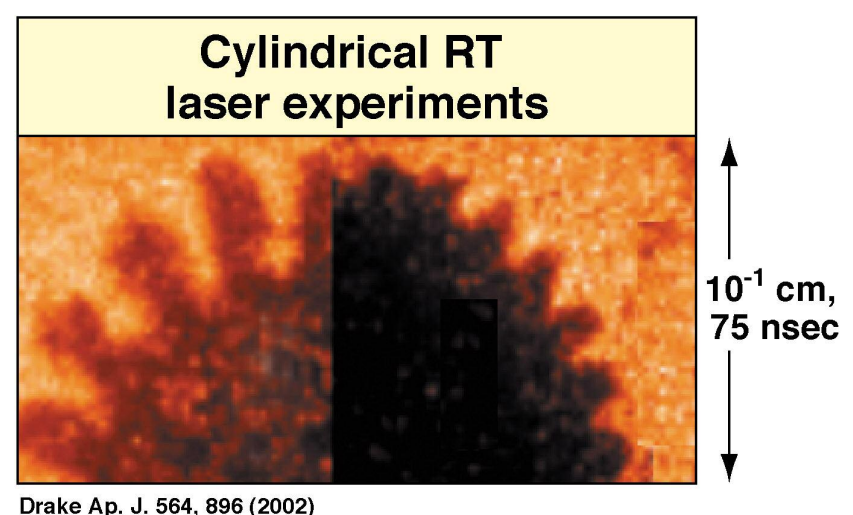

Drake Ap. J. 564, 896 (2002)

Figure 6. Comparison of instabilities generated in a spherical shock model of a supernova, left, with RT experiments conducted on the Omega Laser using scaled targets. The image on the right shows RT growth between 55 and 75 ns on a scale of about $0.1 \mathrm{~cm}$ that is qualitatively similar to the supernova model. 

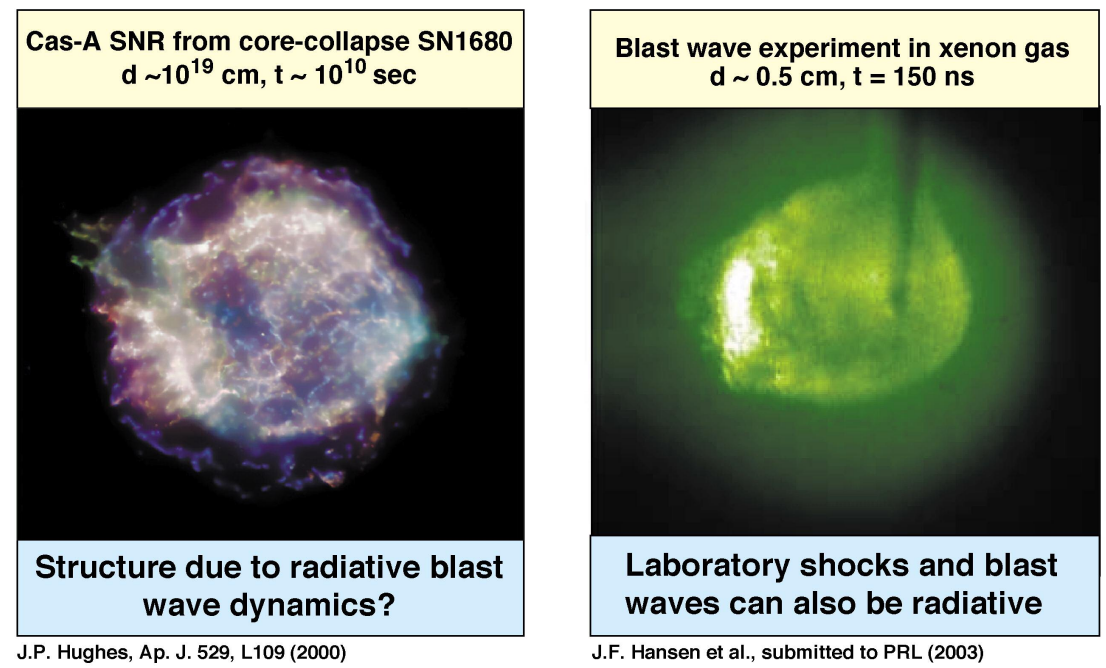

Figure 7. Radiative shocks such as supernova blast waves can be simulated using scaled gas-filled targets illuminated by energetic laser beams. The photograph on the left is a supernova remnant (SNR) in Cassiopeia-A, which occurred in the year 1680 (Chandra X-ray Observatory photograph courtesy of NASA/CXC/SAO). In the image on the right, a $10 \mathrm{~J}$ Janus laser beam incident from the left is focused on the tip of an Fe pin surrounded by xenon gas. The ablated pin material creates an expanding radiatively driven shock that is outrunning the material expansion from the target itself. This is seen as the faint glow surrounding the brighter inner sphere.

Figure 7 compares an astronomical event with a laboratory scaled experiment performed using the Janus laser at LLNL. ${ }^{48}$ Researchers are assessing NIF $s$ potential for simulating exotic astrophysical systems such as the extended RT systems in the Eagle nebula, immense astrophysical radiative magnetohydrodynamic jets, and even possibly the incredible physical conditions that exist only near the surface of a neutron star. ${ }^{49}$ Figure 8 displays examples of these phenomena and associated laser-driven analog experiments performed on Nova and Omega. ${ }^{50,51}$ Note the extreme scaling in time and space between laser experiments and the astrophysical objects in these figures. NIF will provide the capability to study larger-volume targets for longer times and high-fluence. High-energy time-resolved x-ray data will help to validate hydrodynamic models that can be scaled to stellar dimensions and times.
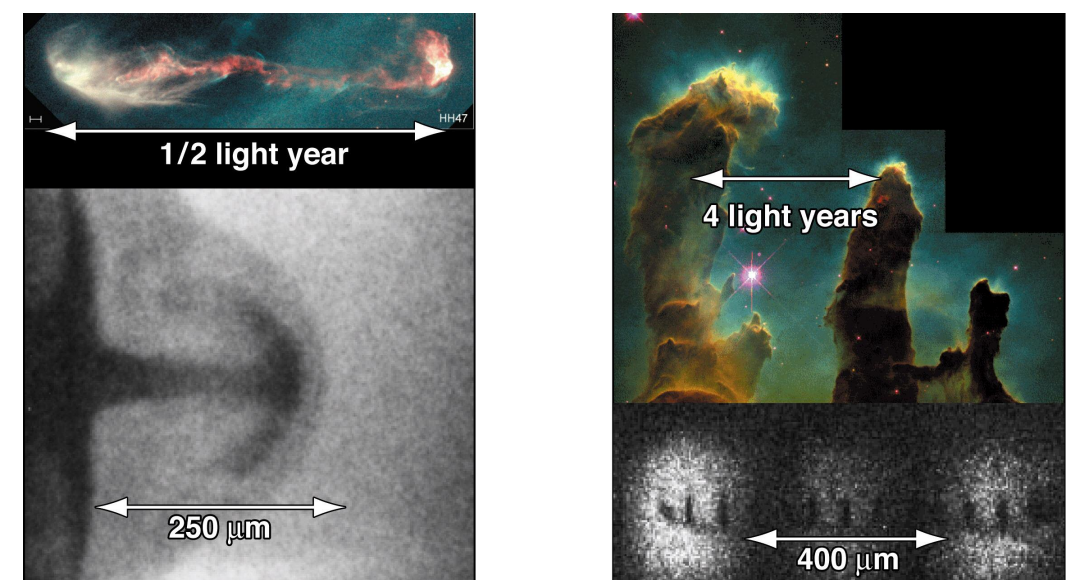

Figure 8. Additional examples of scaled astrophysical phenomena that can be simulated using lasers. On the left is an astrophysical jet (Hubble Space Telescope photograph courtesy of NASA STScI, Release Number: STScI-PRC1995-24a) compared with a laser-generated jet using the Omega laser. ${ }^{50}$ On the right the visually striking structures seen in the Eagle nebula (Hubble Space Telescope photograph courtesy of NASA STScI, Release Number : STScI-1995-44) are compared with similar RT structures generated using the Nova Laser. ${ }^{51}$ 


\section{IGNITION ON NIF}

One of the key missions of NIF is to generate and study thermonuclear ignition and energy gain using the 192 lasers of NIF to compress and heat small capsules containing a mixture of the heavy hydrogen isotopes of deuterium and tritium. Figure 2 illustrated how indirect drive inertial confinement fusion is achieved using NIF. NIF fusion targets use carefully prepared ignition capsules containing the fusion fuel in a thin, very smooth frozen layer surrounding a pressurized DT gas volume. The capsules are precisely formed plastic or copper-doped beryllium shells. The capsule is suspended in a hollow gold cylinder called a hohlraum that has laser entrance windows on each end of the cylinder. Precisely focused temporally-shaped laser beams are directed into the hohlraum through the ends and deliver their energy to the inside walls, generating intense $\mathrm{x}$-rays that uniformly illuminate the capsule. The $\mathrm{x}$ rays ablate the outer surface of the capsule very rapidly. The reaction force from the ablation drives the fusion fuel inward, compressing and heating it to the conditions necessary for thermonuclear fusion reactions to self-initiate. Under the proper conditions, the thermonuclear reactions will propagate outward in a fusion burn, consuming all of the fuel and liberating more energy than was used to drive the target. This type of ICF target is called an indirect-drive target because the laser beams are not incident directly on the fusion capsule. Indirect-drive targets are advantageous because they tend to smooth out imperfections in the laser drive energy and uniformity. However, indirect drive provides less efficient coupling of $\mathrm{x}$-ray energy to the fusion capsule. ${ }^{29,52}$

A second approach to ICF is direct drive, where lasers directly illuminate the fusion capsule. The 60beam Omega laser at the University of Rochester Laboratory for Laser Energetics (LLE) is configured to study direct drive ICF and has been performing ignition experiments for many years. Together, LLE and NIF scientists and engineers have worked to design the NIF switchyards and target chamber to allow reconfiguration of some of its laser beams to a more symmetric arrangement for direct drive ignition studies in the future. ${ }^{53}$ Recent studies by LLE researchers are also looking at "polar" direct drive options, in which beam positioning and timing using NIF's indirect drive configuration of lasers can be optimized to directly drive fusion capsules. ${ }^{54}$

A NIF "point design" ignition hohlraum and capsule has been developed using increasingly sophisticated 3D computer calculations. The most recent calculations, shown in Figure 9, performed on LLNL's ASCI supercomputer system indicates the production of about 20 Megajoules of fusion yield in the form of energetic $14-\mathrm{MeV}$ neutrons, $\mathrm{x}$-rays, and gamma rays for about 2 Megajoules of UV light delivered from the 192 laser beams. ${ }^{55}$

Prospects for ignition on NIF continue to improve. Designs supporting indirect-drive, or x-ray drive of ignition capsules in hohraums are becoming more robust as better physics understanding and better modeling capability, including full 3-dimensional modeling of capsules and hohlraums, allows design trade-off studies to be rapidly performed and design spaces to be optimized. For example, optimization studies have improved plastic capsule performance by a factor of two while allowing ablator roughness to increase by a factor of two, easing fabrication requirements. ${ }^{55}$ 


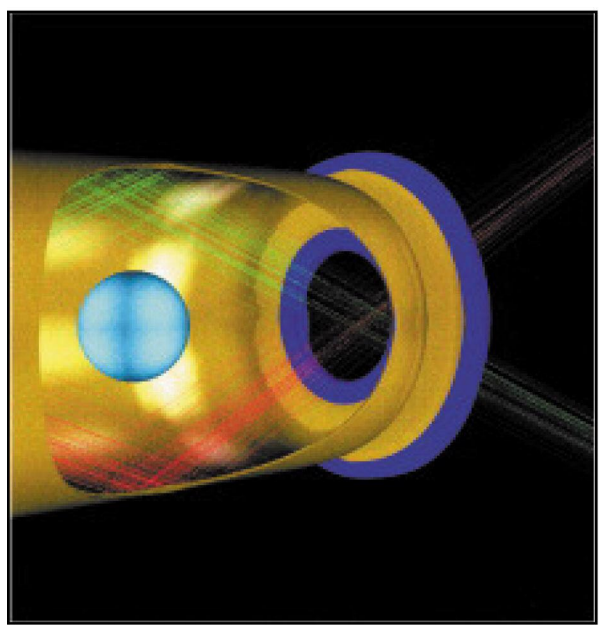

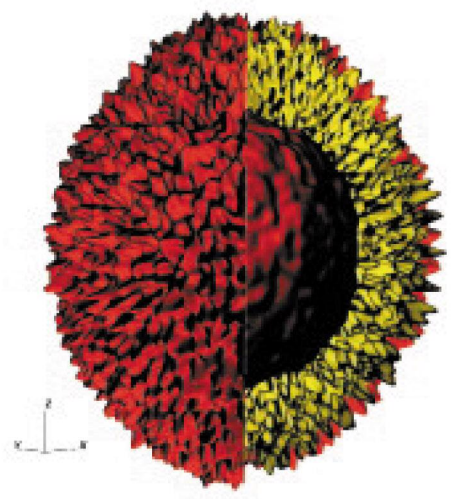

140 ps before ignition time,

$60 \mathrm{~g} / \mathrm{cc}$

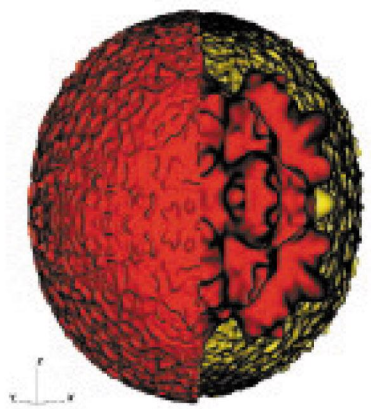

Ignition time, $400 \mathrm{~g} / \mathrm{cc}$ density isosurface (not to scale)

Figure 9. Full 3-D calculation of capsule implosion showing ignition conditions predicted for a point-design NIF ignition target. This calculation used 12.8 million zones and 120 processors and produced a calculated yield of 22 Megajoules. The figure at the left shows one half of the hohlraum with laser beams energy from the right. The figures at the center and right show two different views (and length scales) of the DT capsule as it is undergoing implosion.

New designs developed by researchers at Los Alamos National Laboratory (LANL) using beryllium with graded $\mathrm{Cu}$ dopant are particularly robust, with ablator roughnesses being relaxed by as much as a factor of 10-20 over previous designs and newly optimized polyimide designs, while still producing fusion ignition and energy gain. In addition, significant progress has been made at LANL and at LLE in fabricating smooth and beryllium/copper and plastic capsules that nearly meet these new design specifications. 53,56

Precision control of cryogenic $\mathrm{D}_{2}$ ice smoothness using infrared heating in an isothermal hohlraum has now been demonstrated. ${ }^{57}$ Progress is also being made in developing cryogenic hohlraums with convection mitigation and thermal control. Diffusion filling of a capsule in a hohlraum has also been recently demonstrated and integration of infrared layering, thermal shimming, convection mitigation, and characterization in a $\mathrm{D}_{2}$ test system is under way.

Our increased understanding of fusion target physics and our enhanced computational capabilities are also allowing us to propose target designs that could significantly simplify the preparation and fielding of cryogenic targets on NIF. These designs include extremely narrow micron-diameter fill tubes and graded-dopant beryllium capsules that ease the filling and maintenence of cryogenic DT in the capsule. The fill tube does not significantly impact the implosion characteristics of the capsule based on recent calculations. Figure 10 shows a prototype target using this design. Cryogenic target positioning systems based on this design are currently being developed for use on NIF beginning in 2007 when sufficient beam energy and symmetry is first available. 

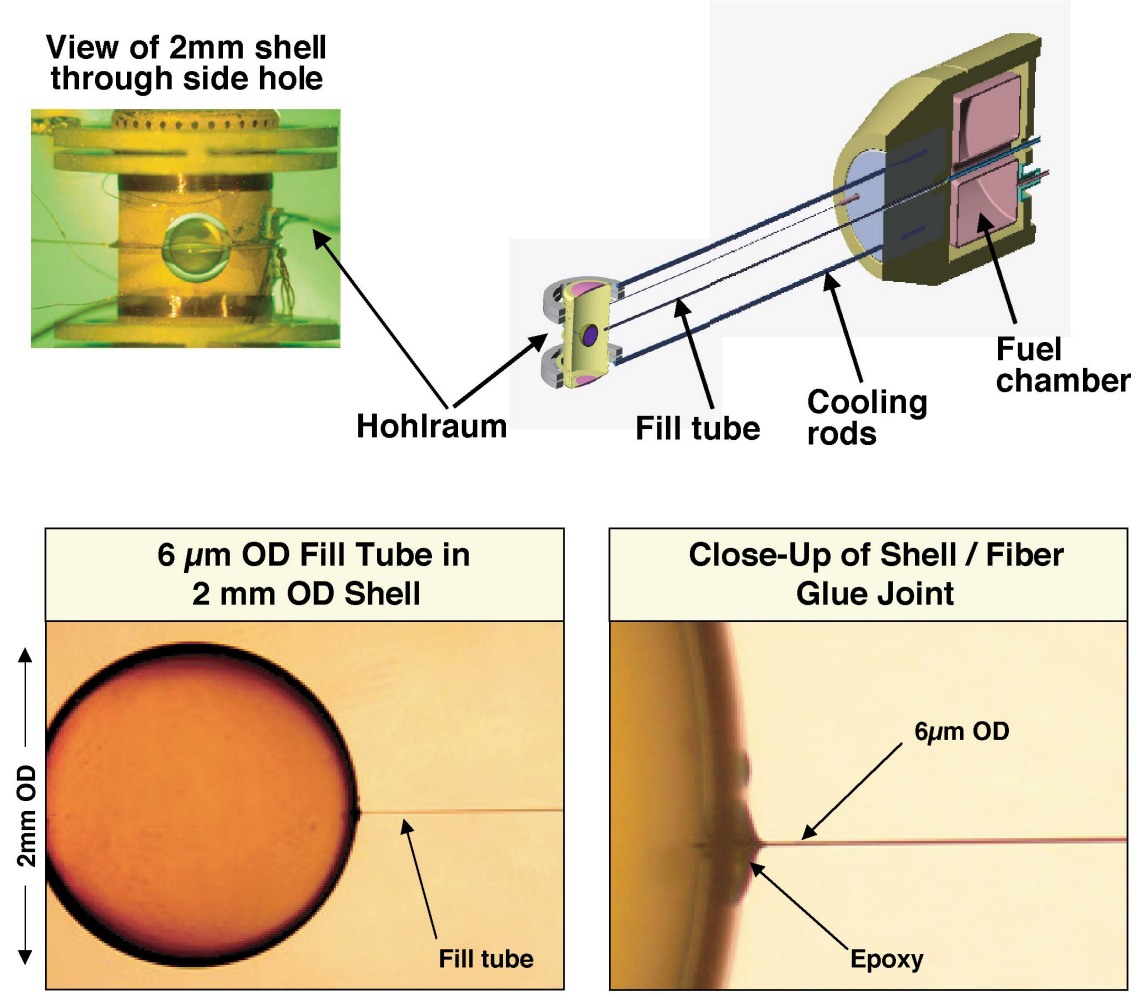

Figure 10. Photograph of a fusion capsule mounted in a hohlraum and a CAD representation of the cryogenic target holder. Other photos show close-ups of the micron-sized fill tube attached to the spherical fusion capsule.

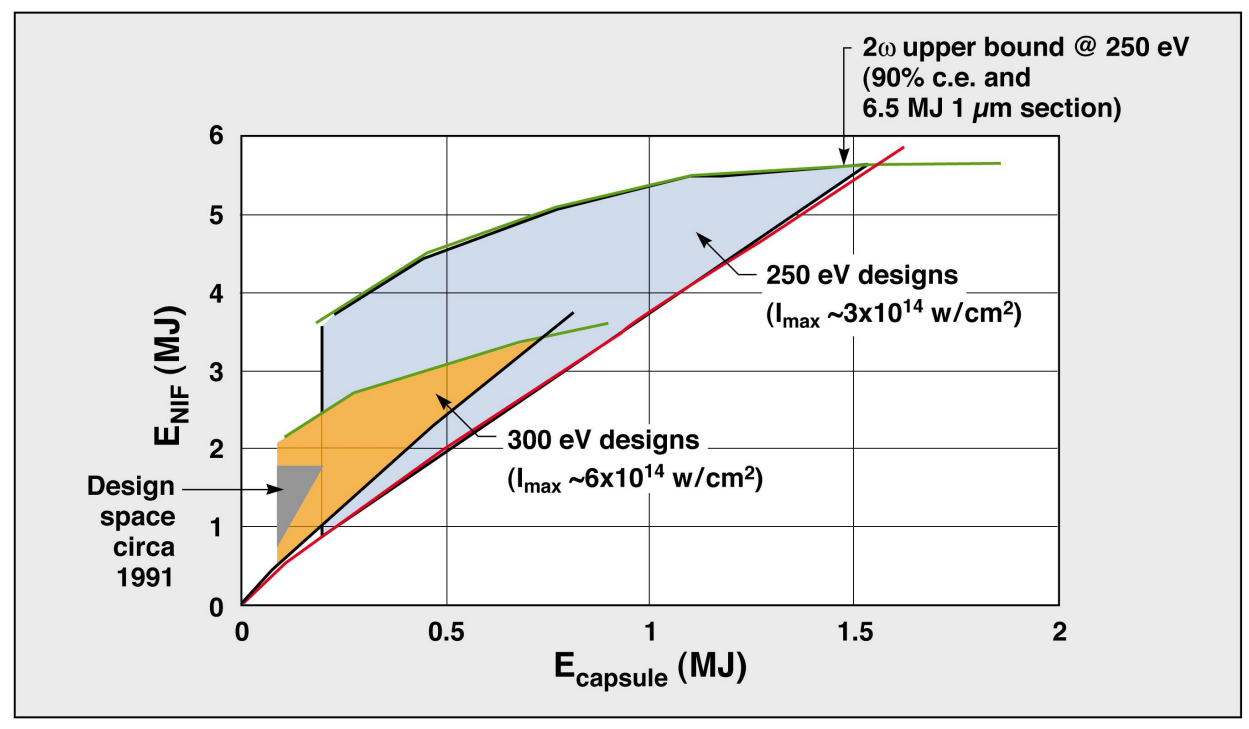

Figure 11. Recent calculations of energy coupled to a fusion capsule from $\mathrm{X}$ rays converted when the laser energy is incident on the hohlraum walls. NIF's design space, as calculated in 1991 during the conceptual design phase of the project, is shown in the lower left of the figure. Recent improvements in modeling and physics understanding lead to a significantly increased design space for $2 \omega$ laser drive. Two extended regions in the figure show that hohlraums can be driven to temperatures of $250 \mathrm{eV}$ and $300 \mathrm{eV}$, indicating that as much as 1.5 Megajoules of x-ray drive energy may couple to a capsule at $250 \mathrm{eV}$. 
Hohlraums driven with green or $2 \omega$ laser light from NIF are also actively being studied. ${ }^{58}$ Figure 11 shows recent calculations suggesting that as much as $1.5 \mathrm{MJ}$ of energy may couple to a capsule at 250$\mathrm{eV}$ drive temperature. However, physical data on $2 \omega$ laser-plasma interactions (LPI) is limited and more work is needed. NIF $2 \omega$ operation has been demonstrated and researchers are studying how to configure some of NIF's early beams for high-energy $2 \omega$ LPI studies.

Finally, fast ignition experiments using the Gekko Laser at the University of Osaka, Institute for Laser Engineering, and the Vulcan Laser at Rutherford Appleton Laboratory in the UK are providing tantalizing glimpses of possible low-energy symmetric heating combined with high-power asymmetric drive to induce hot-spot ignition conditions in cone-focused targets. ${ }^{59-61}$

A "proof-of-principle" fast-ignition experiment at NIF is in the design phase. Laser physicists have determined how NIF's current injection laser, main amplifier, and beam transport system could be modified to allow up to 20 high-energy petawatt-class (HEPW) beams to be directed to target chamber center. Initial experiments are being designed to utilize a single kilojoule-class HEPW beam line with 1-30 picosecond pulse width to drive electron or proton cone-focused ignition experiments. Initial short-pulse capability on NIF is planned to be in place in the 2006 time frame. ${ }^{62}$ Additional HEPW beams in a quad could be installed to provide multi-kilojoule capability.

\section{FIRST PHYSICS FROM NIF}

Over the past year nearly 200 full system shots have been carried out on NIF. In addition a sophisticated suite of experimental diagnostics has been fielded on the 10-meter diameter target chamber and become available for use. These include static and gated $\mathrm{x}$-ray imaging and streak cameras, fullaperture back-scatter system, and a laser interferometer system for measuring shock velocities. The first physics experiments are already being performed on NIF. Initial experiments are studying laserplasma interactions that are important for understanding the propagation of laser beams and the delivery of energy into ignition hohlraums. Other experiments are studying hydrodynamics of materials subjected to laser-driven shocks. Figure 12 shows results from a recent experiment directing NIF's first four beams with $16 \mathrm{~kJ}$ of ultraviolet light into a gas-filled target. The x-ray images compare favorably with sophisticated calculations of laser-plasma interactions. ${ }^{40}$ Figure 13 shows a radiograph of the hydrodynamics of a shocked aluminum jet impinging on low-density carbon foam. In this experiment, two of NIF's laser beams were used to drive the experiment and two other beams, delayed in time, were directed to off-center vanadium foils to provide energetic x-rays for point-projection backlighters. As more NIF beams become available, experimenters can continue these studies by inducing higher energy shocks in materials and can be using additional backlighters with longer delays to study the further time evolution of these systems. 

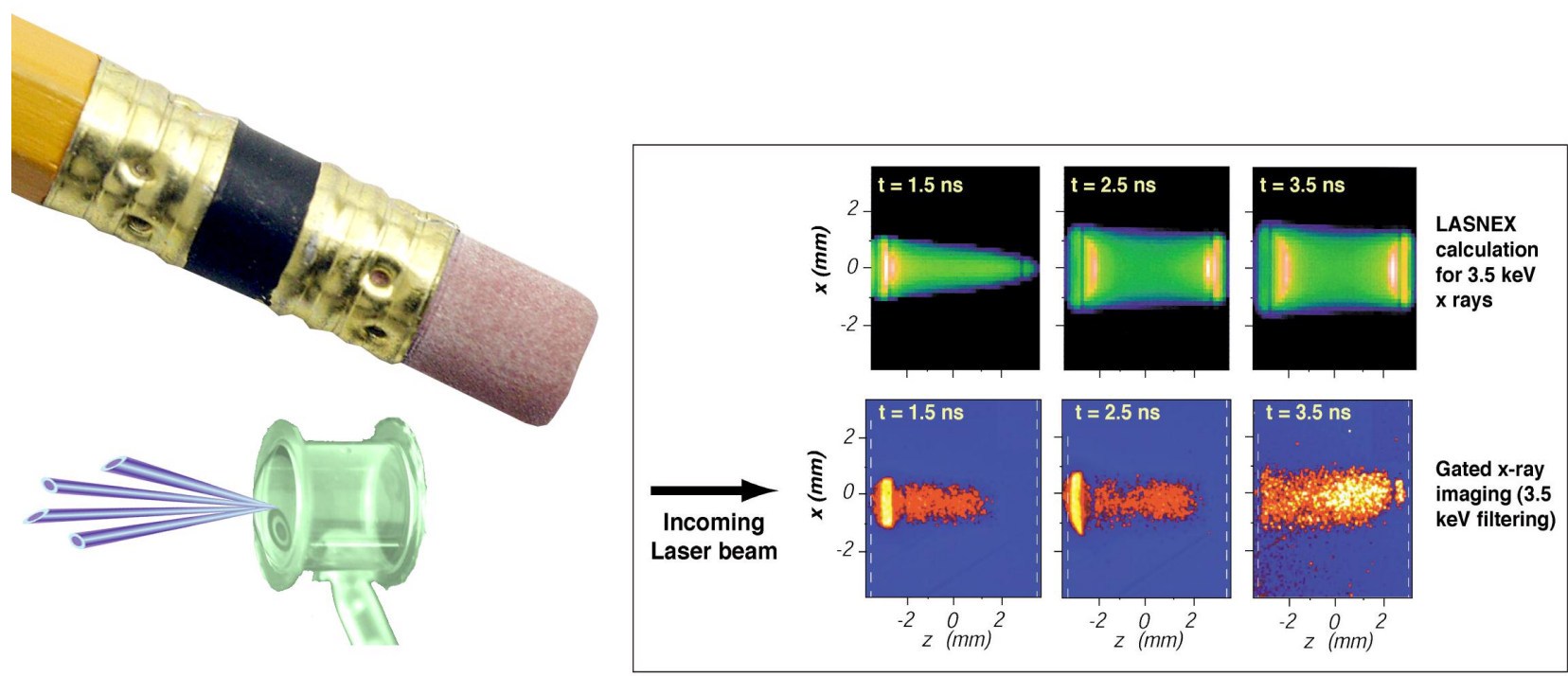

Figure 12. Laser-plasma interaction experiments have been fielded on NIF using $\mathrm{cm}$-scale $\mathrm{CO}_{2}$ gas-filled targets, shown on the left. Results from the first physics experiments on NIF using targets are shown on the right, which are images of $\mathrm{x}$-ray emission using a gated $\mathrm{x}$-ray imaging diagnostic at one ns intervals. This data is compared with computer models that show qualitative agreement.

\section{Two beams of NIF hitting a material sample containing a defect generates:}

- Shock wave pressures of several million atmospheres

- Material temperatures of tens-of thousands of degrees

- A high-speed jet of shocked material moving at greater than $100,000 \mathrm{mph}$ than $1 \mathrm{~mm}$ across
- All in a target measuring less

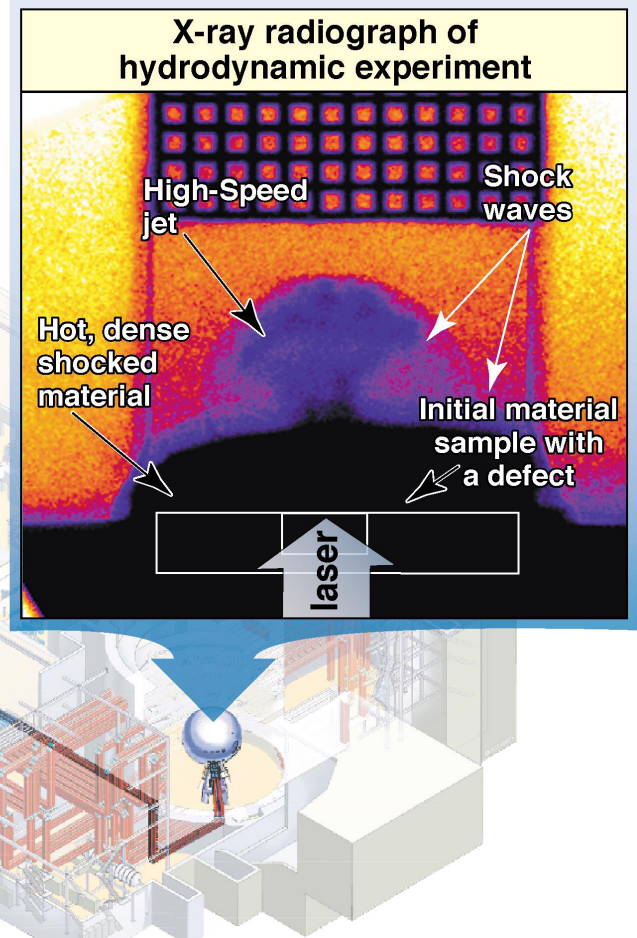

Figure 13. X-ray radiograph of a single-jet hydrodynamics experiment conducted on NIF taken approximately $15 \mathrm{~ns}$ after the main laser pulse. The diameter of the target is approximately $1 \mathrm{~mm}$. A highly supersonic jet of aluminum can be seen interacting with a low-density carbon foam. Two NIF beams were used to drive this experiment, while the other two beams provided separately delayed $\mathrm{x}$-ray backlighter sources. 


\section{THE PATH FORWARD TO FULL NIF}

Completion of all 192 laser beams is scheduled for September 2008. We have developed a plan for beam deployment that supports experiments with steadily increasing capability. We are preparing to commence the build-out of the rest of the laser system beginning in FY 2005. The increasing symmetry and energy available as the number of beams increases enables a variety of target configurations including planar targets, horizontal and vertical half-hohlraums (halfraums), and vertical hohlraums with 4-fold and 8-fold symmetry. After project completion, NIF is expected to ramp up to approximately 700 shots per year for a wide variety of experimental users as a national user facility. A shot campaign conducted on NIF in 2003 provided three target shots per day over a three-day period, giving us confidence in NIF's ability to meet the planned 700 shots per year when it is fully operational. We have also developed a plan for fielding facility diagnostics that is synchronized to the increasing capability NIF provides.

In addition to diagnostics, the NIF Program includes support for building and commissioning facility capabilities in diffractive optics (phase plates), cryogenic target systems, and target area operations. We are also developing a non-ignition cryogenic target capability to be fielded around the time of first cluster of 48 beams.

As NIF matures, we fully expect the facility to evolve to include exciting new capabilities, some of which are mentioned briefly here. The NIF laser system and support buildings have been designed with maximum flexibility for future enhancements such as multi-wavelength operation and highenergy short-pulse operation. NIF is ready to deliver the next generation of HED and ICF experimental capability for the US and international scientific communities. ${ }^{+\dagger}$

\section{ACKNOWLEDGMENTS}

This article reports on the accomplishments of over 3,000 men and women who have worked tirelessly to make NIF a reality. The authors are indebted to the contributions of everyone involved in the National Ignition Facility Project. This work was performed under the auspices of the U.S. Department of Energy by the University of California, Lawrence Livermore National Laboratory under contract W7405-Eng-48.

\section{REFERENCES}

1. J. Lindl, Inertial Confinement Fusion: The Quest for Ignition and Energy Gain Using Indirect Drive, Springer-Verlag, New York (1998).

2. R. Day, A. Hartford, N. Hoffman, W. Lokke, G. McCall, R. Peterson, W. Simmons, R. Sudan, Laboratory Microfusion Capability Phase-II Study, prepared by Interscience, Inc. for the Inertial Fusion Division Office of Research and Advanced Technology, ISI-TM9005281, May 31, 1990.

3. W. F. Krupke, ed., Solid State Lasers for Application to Inertial Confinement Fusion (ICF), , Proc. SPIE Vol. 2633 (1995).

\footnotetext{
${ }^{+\dagger} \square$

www.llnl.gov/nif
} 
4. C. B. Tarter, "Inertial Fusion and High-Energy-Density Science in the United States," Inertial Fusion Sciences and Applications 2001, K. A. Tanaka, D. D. Meyerhofer, J. Meyer-ter-Vehn, eds., Elsevier, Paris, 9-16 (2002).

5. E. Moses et al., "The National Ignition Facility: Status and Plans for Laser Fusion and HighEnergy-Density Experimental Studies," Fusion Science and Technology, Vol. 43, 420 (2003).

6. E. Moses et al., "The National Ignition Facility: 1.8-MJ 750 TW Ultraviolet Laser System," Optical Engineering at the Lawrence Livermore National Laboratory II: The National Ignition Facility, M. A. Lane, C. R. Wuest, eds., Proc. SPIE, Vol. 5341, 13-24 (2004).

7. M. L. Spaeth et al., "National Ignition Facility Requirements and Optical Architecture," Optical Engineering at the Lawrence Livermore National Laboratory II: The National Ignition Facility, M. A. Lane, C. R. Wuest, eds., Proc. SPIE, Vol. 5341, 25-42 (2004), January (2004).

8. R. H. Sawicki, "National Ignition Facility: Laser System, Beam Line Design, and Construction," Optical Engineering at the Lawrence Livermore National Laboratory II: The National Ignition Facility, M. A. Lane, C. R. Wuest, eds., Proc. SPIE, Vol. 5341, 43-54 (2004).

9. B. M. Van Wonterghem, "National Ignition Facility Commissioning and Performance," Optical Engineering at the Lawrence Livermore National Laboratory II: The National Ignition Facility, M. A. Lane, C. R. Wuest, eds., Proc. SPIE, Vol. 5341, 55-65 (2004).

10. W. H. Williams et al., "Optical Propagation Modeling, W. H. Williams," Optical Engineering at the Lawrence Livermore National Laboratory II: The National Ignition Facility, M. A. Lane, C. R. Wuest, eds., Proc. SPIE, Vol. 5341, 66-72 (2004).

11. M. J. Shaw et al., "National Ignition Facility Laser Performance Operations Model (LPOM)," Optical Engineering at the Lawrence Livermore National Laboratory II: The National Ignition Facility, M. A. Lane, C. R. Wuest, eds., Proc. SPIE, Vol. 5341, 73-83 (2004).

12. J. H. Campbell et al., "NIF Advanced Optical Fabrication Technology," Optical Engineering at the Lawrence Livermore National Laboratory II: The National Ignition Facility, Proc. SPIE, Vol. 5341, 84-101 (2004).

13. T. I. Suratwala et al., "Neodymium Glass," Optical Engineering at the Lawrence Livermore National Laboratory II: The National Ignition Facility, M. A. Lane, C. R. Wuest, eds., Proc. SPIE, Vol. 5341, 102-113 (2004).

14. C. J. Stolz et al., "National Ignition Facility Transport Optics," Optical Engineering at the Lawrence Livermore National Laboratory II: The National Ignition Facility, M. A. Lane, C. R. Wuest, eds., Proc. SPIE, Vol. 5341, 114-120 (2004).

15. R. A. Hawley-Fedder et al., "NIF Pockels Cell and Frequency Conversion Crystals," Optical Engineering at the Lawrence Livermore National Laboratory II: The National Ignition Facility, M. A. Lane, C. R. Wuest, eds., Proc. SPIE, Vol. 5341, 121-126 (2004).

16. D. W. Larson, "NIF Laser Hardware: The Line Replaceable Units," Optical Engineering at the Lawrence Livermore National Laboratory II: The National Ignition Facility, M. A. Lane, C. R. Wuest, eds., Proc. SPIE, Vol. 5341, 127-136 (2004).

17. R. E. Bonanno, "Assembling and Installing LRUs for NIF," Optical Engineering at the Lawrence Livermore National Laboratory II: The National Ignition Facility, Proc. SPIE, Vol. 5341, 137-145 (2004).

18. J. Wisoff et al., "Architecture and Performance of the National Ignition Facility Injection Laser System," Optical Engineering at the Lawrence Livermore National Laboratory II: The National Ignition Facility, M. A. Lane, C. R. Wuest, eds., Proc. SPIE, Vol. 5341, 146-155 (2004).

19. P. A. Arnold et al., "Deployment, Commissioning, and Operation of Plasma Electrode Pockels Cells in the National Ignition Facility," Optical Engineering at the Lawrence Livermore National 
Laboratory II: The National Ignition Facility, M. A. Lane, C. R. Wuest, eds., Proc. SPIE, Vol. 5341, 156-167 (2004).

20. R. A. Zacharias et al., "National Ignition Facility Alignment and Wavefront Control," Optical Engineering at the Lawrence Livermore National Laboratory II: The National Ignition Facility, M. A. Lane, C. R. Wuest, eds., Proc. SPIE, Vol. 5341, 168-179 (2004).

21. P. J. Wegner et al., "Final Optics System: Frequency Conversion and Beam Conditioning," Optical Engineering at the Lawrence Livermore National Laboratory II: The National Ignition Facility, M. A. Lane, C. R. Wuest, eds., Proc. SPIE, Vol. 5341, 180-189 (2004).

22. J. Campbell et al., "Continuous Melting of Phosphate Laser Glasses," J. Non-Crystalline Solids $263 \& 264$ (2000).

23. J. Campbell and T. Suratwala, "Nd-doped Phosphate Glasses for High-energy/High-peak-power Lasers," J. Non-Crystalline Solids 263\&264 (2000).

24. C. Boley and M. Rhodes, "Modeling of Plasma Behavior in a Plasma Electrode Pockels Cell," IEEE Trans. Plasma Sci., Vol. 27, No. 3, (1999).

25. M. Newton et al., "Initial Activation and Operation of the Power Conditioning System for the National Ignition Facility," Proc. of the 14th IEEE International Pulsed Power Conference 2003, Dallas, TX, June 15-18, 2003.

26. P. Coyle, ed., "Shiva Laser System," 1976 Laser Program Annual Report, Lawrence Livermore National Laboratory, UCRL-50021-61, 2-54 - 2-183 (1976).

27. W. Simmons and R. Godwin, "Nova Laser Fusion Facility - Design, Engineering, and Assembly Overview," Nucl. Technol./Fusion Vol. 4, 8-24 (1983).

28. J. Paisner et al., "Conceptual Design of the National Ignition Facility," First International Conference on Solid State Lasers for Application to Inertial Confinement Fusion, Proc. SPIE Vol. 2633, 2 (1995).

29. J. Lindl, "Development of the Indirect-Drive Approach to Inertial Confinement Fusion and the Target Physics Basis for Ignition and Gain,” Phys. Plasmas Vol. 2(11), 3933-4024 (1995).

30. T. R. Boehly, R. S. Craxton, T. H. Hinterman, J. H. Kelly, T. J. Kessler, S. A. Kumpan, S. A. Letzring, R. L. McCrory, S. F. B. Morse, W. Seka, S. Skupsky, J. M. Soures, and C. P. Verdon, "The Upgrade to the OMEGA Laser System," Rev. Sci. Instr. Vol 66(1), 508-510 (1995).

31. T. Parham et al., "Developing Optics Finishing Technologies for the National Ignition Facility," Inertial Confinement Fusion Quarterly Report, Lawrence Livermore National Laboratory, UCRLJC-129317, 177-191(1999).

32. D. Aikens et al., "Developing Enabling Optics Finishing Technologies for the National Ignition Facility," Lawrence Livermore National Laboratory, Livermore, CA UCRL-JC-129317, (1998).

33. P. Baisden, "National Ignition Facility (NIF) program update," Lawrence Livermore National Laboratory, Livermore, CA UCRL-JC-137357, (2000).

34. J. Lawson et al., "Surface Figure and Roughness Tolerances for NIF Optics and the Interpretation of the Gradient, P-V Wavefront, and RMS Specifications," Optical Manufacturing and Testing III, H. Philip Stahl, ed., Proc. SPIE Vol. 3782, 510-517 (1999).

35. B. Stuart et al., "Laser-induced Damage in Dielectrics with Nanosecond to Sub-picosecond Pulses," Phys. Rev. Lett., Vol. 74, 2248-51 (1995).

36. J. Menapace et al., "Combined Advanced Finishing and UV Laser Conditioning for Producing UV-damage-resistant Fused Silica Optics," Proc. SPIE Vol. 4679, 56-69 (2002).

37. R. Brusasco et al., "Localized $\mathrm{CO}_{2}$ Laser Treatment for Mitigation of 351-nm Damage Growth on Fused Silica," Proc. SPIE Vol. 4679, 40-47 (2002). 
38. C. Stolz et al., "Fabrication of Meter-scale Laser Resistant Mirrors for the National Ignition Facility, a Fusion Laser," Advances in Mirror Technology for X-ray, EUV Lithography, Laser, and Other Applications, A. Khounsary, U. Dinger, K, Ota, eds., Proc. SPIE Vol. 5193, 50-58 (2004).

39. M. Landon et al., "Design of the National Ignition Facility Static X-ray Imager," Rev. Sci. Instr. Vol. 72 No. 1, 698-700 (2001).

40. S. Glenzer et al., Progress in Long Scale Length Laser-Plasma Interactions, Inertial Fusion Sciences and Applications 2003, B. A. Hammel, D. D. Meyerhofer, J. Meyer-ter-Vehn, H. Azechi, eds., American Nuclear Society, Lagrange Park, 207-212 (2004).

41. R. Davidson, ed., Frontiers in High Energy Density Physics: The X-Games of Contemporary Science, National Academies Press, Washington D.C. (2003).

42. M. Turner, ed., Connecting Quarks with the Cosmos: Eleven Science Questions for the New Century, National Academies Press (2003).

43. B. Remington et al., "Materials Science at the Extremes of Pressure and Strain Rate," Inertial Fusion Sciences and Applications 2003, B. A. Hammel, D. D. Meyerhofer, J. Meyer-ter-Vehn, H. Azechi, eds., American Nuclear Society, Lagrange Park, 917-921 (2004).

44. M. Perry et al., Rev. Sci. Instr., Vol. 70, 265 (1999).

45. B. Remington, "High Energy Density Astrophysics in the Laboratory," Inertial Fusion Sciences and Applications 2001, K. A. Tanaka, D. D. Meyerhofer, J. Meyer-ter-Vehn, eds., Elsevier, Paris, 1003-1028 (2002).

46. P. Drake et al., Astrophys. J. Vol. 564, 896 (2002).

47. K. Kifonidis et al., Astrophys. J. Vol. 531, L123 (2000).

48. J. Hansen et al., "Laboratory Simulations of Supernova Shockwave Propagation and ISM Interaction," Inertial Fusion Sciences and Applications 2003, B. A. Hammel, D. D. Meyerhofer, J. Meyer-ter-Vehn, H. Azechi, eds., American Nuclear Society, Lagrange Park, 962-965 (2004).

49. R. Klein et al., Astrophys. J. 457, L85 (1996).

50. J. Foster et al., Phys. Plasmas 9, 2251 (2002).

51. B.. Remington et al., Phys. Fluids B 5, 2588 (1993).

52. S. Haan et al., "Update on NIF Indirect Drive Target Design," Inertial Fusion Sciences and Applications 2001, K. A. Tanaka, D. D. Meyerhofer, J. Meyer-ter-Vehn, eds., Elsevier, 207-211 (2002).

53. R. McCrory, "Progress in Inertial Confinement Fusion Research in the United States," Inertial Fusion Sciences and Applications 2003, B. A. Hammel, D. D. Meyerhofer, J. Meyer-ter-Vehn, H. Azechi, eds., American Nuclear Society, Lagrange Park, 3-8 (2004).

54. S. Skupsky et al., "Advanced Direct-Drive Target Designs for the NIF," Inertial Fusion Sciences and Applications 2003, B. A. Hammel, D. D. Meyerhofer, J. Meyer-ter-Vehn, H. Azechi, eds., American Nuclear Society, Lagrange Park, 61-64 (2004).

55. S. Haan et al., "Update on Indirect Drive Ignition Target Designs for NIF," Inertial Fusion Sciences and Applications 2003, B. A. Hammel, D. D. Meyerhofer, J. Meyer-ter-Vehn, H. Azechi, eds., American Nuclear Society, Lagrange Park, 55-60 (2004).

56. A. Nobile et al., "Development of Beryllium-Copper Alloy Ignition Capsules," Inertial Fusion Sciences and Applications 2003, B. A. Hammel, D. D. Meyerhofer, J. Meyer-ter-Vehn, H. Azechi, eds., American Nuclear Society, Lagrange Park, 753-757 (2004).

57. B. Kozioziemski et al., "Demonstration of Symmetry Control of Infrared Heated Deuterium Layers in Hohlraums," Inertial Fusion Sciences and Applications 2003, B. A. Hammel, D. D. Meyerhofer, J. Meyer-ter-Vehn, H. Azechi, eds., American Nuclear Society, Lagrange Park, $762-765$ (2004). 
58. L. Suter, "Prospects for High-gain, High-yield NIF Targets Driven by $2 \omega$ Light," Inertial Fusion Sciences and Applications 2003, B. A. Hammel, D. D. Meyerhofer, J. Meyer-ter-Vehn, H. Azechi, eds., American Nuclear Society, Lagrange Park, 23-34 (2004).

59. K. Mima et al., Recent Progress of Implosion Experiments with Uniformity-improved GEKKO XII Laser Facility at the Institute of Laser Engineering, Osaka University, Phys. Plasmas, Vol. 3(5), 2077-2083 (1996).

60. R. Kodama et al., "Fast Heating With a Petawatt Laser as a Step to Ignition," Inertial Fusion Sciences and Applications 2003, B. A. Hammel, D. D. Meyerhofer, J. Meyer-ter-Vehn, H. Azechi, eds., American Nuclear Society, Lagrange Park, 333-338 (2004).

61. R. Edwards et al., "Experimental Investigation of the Transport of Electron Beams Generated by the Vulcan Petawatt Laser," Inertial Fusion Sciences and Applications 2003, B. A. Hammel, D. D. Meyerhofer, J. Meyer-ter-Vehn, H. Azechi, eds., American Nuclear Society, Lagrange Park, 344348 (2004).

62. C. P. J. Barty et al., "Technical Challenges and Motivations for High Energy Petawatt Lasers on NIF," Inertial Fusion Sciences and Applications 2003, CA, B. A. Hammel, D. D. Meyerhofer, J. Meyer-ter-Vehn, H. Azechi, eds., American Nuclear Society, Lagrange Park, 612-615 (2004). 